OPEN ACCESS

Edited by:

Junmin Zhang,

Lanzhou University, China

Reviewed by:

Jiwei Yu,

Shanghai Jiao-Tong University, China Mirna Jovanovic,

University of Belgrade, Serbia

*Correspondence:

Mi-Kyoung Kwak

mkwak@catholic.ac.kr

Specialty section:

This article was submitted to Cancer Molecular Targets

and Therapeutics,

a section of the journal

Frontiers in Oncology

Received: 03 November 2021

Accepted: 27 December 2021

Published: 26 January 2022

Citation:

Park J, Kim SK, Hallis SP, Choi B-H and Kwak M-K (2022) Role of

CD133/NRF2 Axis in the

Development of Colon Cancer

Stem Cell-Like Properties.

Front. Oncol. 11:808300.

doi: 10.3389/fonc. 2021.808300

\section{Role of CD133/NRF2 Axis in the Development of Colon Cancer Stem Cell-Like Properties}

\author{
Jimin Park ${ }^{1}$, Seung Ki Kim ${ }^{1}$, Steffanus Pranoto Hallis ${ }^{1}$, Bo-Hyun Choi ${ }^{2}$ \\ and Mi-Kyoung Kwak ${ }^{1,3,4 *}$
}

1 Department of Pharmacy and BK21FOUR Advanced Program for SmartPharma Leaders, Graduate School of The Catholic University of Korea, Gyeonggi-do, South Korea, ${ }^{2}$ Department of Pharmacology, School of Medicine, Daegu Catholic University, Daegu, South Korea, ${ }^{3}$ Integrated Research Institute for Pharmaceutical Sciences, The Catholic University of Korea, Gyeonggi-do, South Korea, ${ }^{4}$ College of Pharmacy, The Catholic University of Korea, Gyeonggi-do, South Korea

Cancer stem cells (CSCs) exhibit intrinsic therapy/stress resistance, which often cause cancer recurrence after therapy. In this study, we investigated the potential relationship between the cluster of differentiation (CD)-133, a CSC marker of colon cancer, and nuclear factor erythroid 2-like 2 (NFE2L2; NRF2), a master transcription factor for the regulation of multiple antioxidant genes. In the first model of CSC, a sphere culture of the colorectal cell line HCT116, showed increased levels of CD133 and NRF2. Silencing of CD133 reduced the levels of CSC markers, such as Kruppel-like factor 4 (KLF4) and ATPbinding cassette subfamily $\mathrm{G}$ member 2 (ABCG2), and further suppressed the expression levels of NRF2 and its target genes. As a potential molecular link, CD133-mediated activation of phosphoinositide 3-kinase/serine-threonine kinase (PI3K/AKT) signaling appears to increase the NRF2 protein levels via phosphorylation and the consequent inhibition of glycogen synthase kinase (GSK)-3ß. Additionally, NRF2-silenced HCT116 cells showed attenuated sphere formation capacity and reduced CSC markers expression, indicating the critical role of the NRF2 pathway in the development of CSClike properties. As a second model of CSC, the CD133 ${ }^{\text {high }}$ cell population was isolated from HCT116 cells. CSC-like properties, including sphere formation, motility, migration, colony formation, and anticancer resistance, were enhanced in the CD133 ${ }^{\text {high }}$ population compared to $\mathrm{CD} 133^{\text {low }} \mathrm{HCT} 116$ cells. Levels of NRF2, which were elevated in CD133 ${ }^{\text {high }}$ HCT116, were suppressed by CD133-silencing. In line with these, the analysis of The Cancer Genome Atlas (TCGA) database showed that high levels of CD133 expression are correlated with increased NRF2 signaling, and alterations in CD133 gene or expression are associated with unfavorable clinical outcome in colorectal carcinoma patients. These results indicate that the CD133/NRF2 axis contributes to the development of CSC-like properties in colon cancer cells, and that PI3K/AKT signaling activation is involved in CD133-mediated NRF2 activation.

Keywords: CD133, cancer stem cell, NRF2, PI3K/AKT/GSK-3ß, sphere formation, colorectal cancer 


\section{INTRODUCTION}

Cancer stem cell (CSC) is a subpopulation of tumor cells, which is known to account for $1-2 \%$ of tumors. Initially, Dick and colleagues identified the leukemia-initiating cluster of differentiation (CD) $-34^{+} \mathrm{CD} 38^{-}$cells from acute myeloid leukemia (AML) and showed that these cell fractions have differentiation and self-renewal capacities using serial transplantation in immunodeficient mice (1). CSCs share several common characteristics with normal stem cells, including self-renewal capacity, asymmetric division, and differentiation potential (2-4). In addition, CSCs attribute core characteristics to aggressive cancers due to their intrinsic resistance to anticancer treatment. Upregulation of drug efflux transporters, increased expression of the reactive oxygen species (ROS) scavenging system, and promotion of DNA damage repair are observed in CSCs, which enhance their survival in response to chemo- and radiotherapy (5-9). Several cell surface molecules, such as $\mathrm{CD} 44, \mathrm{CD} 133$, and ATP-binding cassette subfamily G member 2 (ABCG2), and transcription factors, such as Kruppellike factor 4 (KLF4) and octamer-binding transcription factor 4 (OCT4), have been used to isolate and characterize CSCs $(2,8$, $10,11)$

CD133 (Prominin-1) is a transmembrane penta-span glycoprotein localized in cholesterol-based lipid rafts in the plasma membrane (12). It has two large extracellular loops, an $\mathrm{N}$-terminal extracellular domain and a C-terminal intracellular domain, and eight glycosylation sites. Since its first identification in human hematopoietic stem cells (13), CD133 has been recognized as a marker of CSCs (14). The CD133-positive population was identified as $2.5 \%$ of the total tumor cells from colon cancer tissues and reproduced original tumors in immunodeficient mice (15). In an animal model of renal capsule transplantation, all colon cancer-initiating cells were CD133-positive, while CD133-negative cells, which comprised majority of cancer specimens, were not able to initiate tumorigenesis (16). High CD133 expression in colorectal cancer is correlated with low survival of patients with cancer (17). Furthermore, CD133 expression is associated with an aggressive cancer phenotype. CD133 overexpression in pancreatic cancer cells induced epithelial-mesenchymal transition (EMT) and enhanced cancer metastasis in athymic mice (18). CD133-positive cells from primary non-small cell lung cancer (NSCLC) specimens exhibited higher levels of genes associated with stemness, migration, and drug efflux than CD133-negative cells (19). Additionally, cisplatin treatment in primary tumor xenografts showed that the CD133-positive population survived after therapy. Suppression of ABCG2 in CD133-positive colon cancer cells enhances their apoptotic response to chemotherapy (20).

Nuclear factor erythroid 2-like 2 (NFE2L2/NRF2) is a cap'n'collar (CNC) transcription factor containing a basic leucine zipper (bZip) domain. Under normal conditions, NRF2 binds to the cytoplasmic protein, Kelch-like $\mathrm{ECH}$-associated protein (KEAP1) and is subjected to proteasomal degradation via the formation of the KEAP1/Cul3/Rbx1 E3 ligase complex (21). In the presence of oxidative/electrophilic stress, NRF2 is liberated from KEAP1 and translocated into the nucleus where it binds to the antioxidant response element (ARE) of the promoter regions of an array of genes $(22,23)$. These genes encode various cytoprotective proteins, including detoxifying enzymes (e.g., $\mathrm{NAD}(\mathrm{P}) \mathrm{H}$ : quinone oxidoreductase-1 [NQO1], aldo-keto reductase $1 \mathrm{C} 1$ [AKR1C1]), antioxidant proteins (e.g., glutamate-cysteine ligase catalytic subunit [GCLC], glutathione peroxidase 1 [GPX1]), heme metabolizing enzymes (e.g., heme oxygenase-1 [HO-1]), and drug efflux transporters (e.g., breast cancer resistance protein [BCRP/ABCG2], multi-drug resistance-1 [MDR1/ABCB1]) $(21,23,24)$. NRF2 is accepted as a critical component of cellular defense systems that cope with oxidative and environmental stress by removing intracellular ROS/electrophiles, thereby maintaining cellular redox homeostasis $(25,26)$. In addition to KEAP1, glycogen synthase

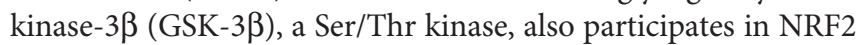
regulation $(27,28)$. GSK-3 $\beta$ phosphorylates NRF2 and promotes $\beta$-transducin repeat-containing protein ( $\beta$-TRCP)-dependent ubiquitination and subsequent proteasomal degradation (27, 29). Since GSK-3 $\beta$ activity is inhibited by phosphoinositide 3kinase (PI3K)/protein kinase B (AKT)-mediated phosphorylation, PI3K/AKT activation results in the blockade of $\beta$-TRCP-dependent NRF2 degradation $(27,30)$.

Although NRF2 shows protective roles in normal cells under stressful conditions, elevated levels of NRF2 in cancers promote cancer cell survival and facilitate tumor growth, cancer progression, and development of resistance to therapy (31-33). In particular, there is evidence that NRF2 signaling is upregulated in several types of CSC models, such as tumor spheres, CD $44^{\text {high }}$ cells, and aldehyde dehydrogenase $(\mathrm{ALDH})^{\text {high }}$ cancer cells. Additionally, this upregulation was responsible for the development of CSC-like properties, including therapy resistance, spheroid growth, enhanced migration capacity, and facilitated tumor growth (34-39). In the present study, we investigated the potential relationship between CSC markers, CD133 and NRF2, in colon cancer cells and demonstrated the role of the CD133/NRF2 axis in the development of CSC-like properties using two CSC models of spheroid culture system and CD133 ${ }^{\text {high }}$ subpopulation system.

\section{MATERIALS AND METHODS}

\section{Materials}

Doxorubicin, 3-(4,5-dimethylthiazol-2-yl)-2,5-diphenyltetrazolium bromide (MTT), and LY294002 were purchased from SigmaAldrich (St. Louis, MO, USA). Lipofectamine RNA iMAX was purchased from Invitrogen Life Technologies (Carlsbad, CA, USA). Agarose was purchased from Promega Corp. (Madison, WI, USA). Antibodies recognizing NRF2 (sc-13032), NQO1 (sc-16464), and glyceraldehyde 3-phosphate dehydrogenase (GAPDH; sc-47724) were obtained from Santa Cruz Biotechnology (Dallas, TX, USA). Antibodies against AKT (\#4691S), p-AKT (S473; \#4060S), GSK-3 $\beta$ (\#9315S), p-GSK-3ß (S9; \#9336S), KLF4 (\#4038S), ABCG2 (\#4477S), and CD133 (\#5860S) were purchased from Cell Signaling Technology (Danvers, MA, USA). Anti-AKR1C1 (H00001645-B01P), anti-GCLC (ab207777), and anti-HO-1 
(ADI-SPA-896) antibodies were purchased from Abnova (Walnut, CA, USA), Abcam (Cambridge, UK), and Enzo Life Sciences (Farmingdale, NY, USA), respectively. Allophycocyanin (APC)conjugated CD133 (25-110-963-110-963) antibody and its control IgG (25-113-434-113-434) were purchased from Miltenyi Biotec (Bergisch Gladbach, NW, Germany). TB Green Premix Ex Taq was obtained from Takara Bio (Kusatsu, Shiga, Japan). Ultra-low attachment culture dishes or 6-well plates for sphere culture were obtained from Corning Costar Corp. (Cambridge, MA, USA). Gene-specific small interfering RNAs (siRNAs), CD133 siRNA, NRF2 siRNA, and non-specific scrambled control siRNA, were obtained from Bioneer Corp. (Daejeon, Republic of Korea).

\section{Cell Culture}

The human colorectal carcinoma cell line, HCT116, was purchased from the American Type Culture Collection (Rockville, MD, USA). Cells were cultured in Dulbecco's modified Eagle's medium (DMEM; Welgene Inc., Daegu, Republic of Korea) and Nutrient Mixture F-12 medium (Welgene Inc.) supplemented with $10 \%$ fetal bovine serum (FBS; Corning Costar Corp.) and $1 \%$ penicillin/streptomycin (Welgene Inc.). The cells were grown at $37^{\circ} \mathrm{C}$ in a humidified atmosphere containing 5\% carbon dioxide $\left(\mathrm{CO}_{2}\right)$. Colorectal cancer cell line Colo205, pancreatic carcinoma cell line PANC1 and MIA PaCa-2, and breast carcinoma cell line MCF-7 were purchased from ATCC, and were grown in RPMI1640 (Colo205) and DMEM (PAC-1, MIA PaCa-2, MCF-7).

\section{Sphere Culture}

Cells were plated at a density of $1 \times 10^{5}$ cells $/ \mathrm{mL}$ in ultralow attachment $100 \mathrm{~mm}$ plates or 6-well plates. The cells were grown in serum-free DMEM and Nutrient Mixture F-12 medium supplemented with B27 (Life Technologies), $20 \mathrm{ng} / \mathrm{mL}$ epithelial growth factor, $20 \mathrm{ng} / \mathrm{mL}$ basic fibroblast growth factor (R\&D Systems, Minneapolis, MN, USA), $5 \mathrm{mg} / \mathrm{mL}$ bovine insulin (Cell Applications Inc., San Diego, CA, USA), $0.5 \mathrm{mg} / \mathrm{mL}$ hydrocortisone (Sigma-Aldrich), and penicillin/ streptomycin. In sphere culture conditions, HCT116 cells were grown for 3-6 d and then harvested as described previously (37). The sphere number and size were counted using ToupView software (ToupTek, Hangzhou, Zhejiang, China).

\section{siRNA Transfection}

Cells were seeded at a density of $2 \times 10^{5}$ cells in a $60 \mathrm{~mm}$ dish and grown for $2 \mathrm{~d}$. The medium was changed to antibiotic-free DMEM and Nutrient Mixture F-12 medium with 10\% FBS. The cells were transfected with final concentration of $10 \mathrm{nmol}$ predesigned CD133-specific siRNA (3'-GUCUACAAGGA CUUUCCAA- ${ }^{\prime}$ and $3^{\prime}$-UUGGAAAGUCCUUGUAGAC-5') or NRF2-specific siRNA (3'-GAGACUACCAUGGUUCCAA$5^{\prime}$ and $3^{\prime}$-UUGGAACCAUGGUAGUCUC-5'), or scrambled control siRNA using (1:3) volume ratio of Lipofectamine RNAiMAX reagent (Invitrogen Life Technologies) according to manufacturer's protocol. After $24 \mathrm{~h}$, the transfection complexcontaining medium was removed, and the cells were further cultured for $24 \mathrm{~h}$ for recovery in complete medium (36).

\section{Immunoblotting Analysis}

Whole lysates were prepared by adding $5 \mathrm{X}$ sample buffer containing $250 \mathrm{mM}$ Tris- $\mathrm{HCl}(\mathrm{pH} 6.8), 10 \%$ sodium dodecyl sulfate (SDS; Biosesang, Gyeonggi-do, Korea), 30\% glycerol, $0.25 \%$ bromophenol blue, and 5\% $\beta$-mercaptoethanol (SigmaAldrich, Co.). Protein samples were separated in $8-10 \%$ SDSpolyacrylamide gels and then transferred to nitrocellulose membranes (Whatman GmbH, Dassel, Germany). The membranes were blocked with 5\% skim milk for $1 \mathrm{~h}$ and then incubated with the primary antibody in $3 \%$ bovine serum albumin (BSA) overnight. After incubation with the secondary antibody, chemiluminescent images were detected using a LAS4000 mini-imager (GE Healthcare Life Sciences, Piscataway, NJ, USA). The loading control was detected after antibodies removal using stripping buffer (Restore Western blot stripping buffer; Thermo Fischer Scientific Inc., Waltham, MA, USA) followed by membrane blocking, primary and secondary antibodies incubation, and chemiluminescent detection as described previously.

\section{Total RNA Extraction and Real-Time Reverse Transcription-Polymerase Chain Reaction (RT-PCR) Analysis}

Total RNA was isolated using TRIzol reagent (Thermo Fisher Scientific Inc., Waltham, MA, USA) and processed for cDNA synthesis. RT reactions were performed by incubating $200 \mathrm{ng}$ of total RNA with a reaction mixture containing oligo (dT), Go script $5 \mathrm{X}$ buffer, $\mathrm{MgCl}_{2}(25 \mathrm{mM}$ ), and dNTP (2 mM) (Promega Corp.). Relative quantification of real-time RT-PCR was carried out using a Roche Light Cycler (Mannheim, Germany) with the Takara TB Premix ExTaq System (Otsu, Japan) as described previously (40). Primers were synthesized by Bioneer Corp., and the primer sequences for human genes were as follows: Hypoxanthine phosphoribosyltransferase-1 (HPRT1), 5'TGGCGTCGTGATTAGTGATG-3' and 5'-GCTACAATG TGATGGCCTCC-3', 5'-CCTGGCGTCGTGATTAGTGA-3' and $5^{\prime}$-GCTACAATGTGATGGCCTCC-3', 5'-TGACACTGG CAAAACAATGC- $3^{\prime}$ and 5'-CAAATCCAACAAAGTCTGGC3'; ABCG2, 5'-CACAACCATTGCATCTTGGCTG-3' and 5'TGAGAGATCGATGCCCTGCTTT-3'; KLF4, 5'-ACACTTG TGATTACGCGGGCTGC-3' and 5'-GGCGAATTTCCATCC ACAGCCG-3'; CD133, 5'-CCGCAGGAGTGAATCTTTTA-3' and 5'-CTATAGGAAGGACTCGTTGC-3'; NRF2, 5'-TAGCA ATGAAGACTGGGCTC- $3^{\prime}$ and $5^{\prime}$-CCAGTGGATCTGC CAACTAC-3'; NQO1, 5'-CAGTGGTTTGGAGTCCCTGCC-3' and 5'-TCCCCGTGGATCCCTTGCAG-3'; AKR1C1, 5'GAAAGAAACATTTGCCAGCC-3' and 5'-TGAGCAGAAT CAATATGGCG-3'; GCLC, 5'-TGAAGGGACACCAGGAC AGCC-3' and 5'-GCAGTGTGAACCCAGGACAGC-3'; HO-1, $5^{\prime}$-GCTGCTGACCCATGACACCAAGG-3' and 5'-AAGGAC CCATCGGAGAAGCGGAG-3'; GPx1, 5'-TTCCCGTGCAAC CAGTTTG-3' and 5'-TTCACCTCGCACTTCTCGAA-3'.

\section{Flow Cytometry and Cell Sorting}

Approximately $1 \times 10^{6}$ HCT116 cells were harvested and incubated in $2 \mu \mathrm{L}$ CD133/1-APC staining dye (Miltenyi Biotec) 
with $98 \mu \mathrm{L}$ buffer containing $2 \mathrm{mM}$ ethylenediaminetetraacetic acid (EDTA) and 2\% FBS for $40 \mathrm{~min}$. IgG control samples were incubated with $2 \mu \mathrm{L}$ REA control (S)-APC staining dye (Miltenyibiotec Korea) with $98 \mu \mathrm{L}$ of buffer. The fluorescence intensity of the stained cells was analyzed using an FACS Aria III cell sorter flow cytometer (BD Biosciences, Franklin Lakes, NJ, USA), and CD $133^{\text {high }}$ and CD133 ${ }^{\text {low }}$ subpopulations were sorted as described previously (35).

\section{MTT Assay}

Cells were plated at a density of $3 \times 10^{3}$ cells/well in a 96-well plate and incubated with doxorubicin for $24 \mathrm{~h}$. After the addition of MTT solution $(2 \mathrm{mg} / \mathrm{mL})$, the cells were further incubated for $4 \mathrm{~h}$. The MTT solution was removed, $100 \mu \mathrm{L} /$ well of dimethyl sulfoxide (DMSO; Sigma-Aldrich Co.) was added, and the absorbance was measured at $540 \mathrm{~nm}$ using SpectraMax (Molecular Devices, San Jose, CA, USA) (41).

\section{Wound Healing Assay}

To determine cell motility, CD $133^{\text {high }}$ and CD $133^{\text {low }}$ cells were plated in a 12 -well plate at a density of $2.5 \times 10^{5}$ cells/well. When 95-100\% confluency was achieved, a straight scratch was made on the surface using a pipette tip. Then, the cells were grown for 24 or $48 \mathrm{~h}$ in serum-free medium, and the migration of cells into the wounded area was photographed using a JULI ${ }^{\mathrm{TM}}$ Smart fluorescent cell analyzer (Digital Bio source, Seoul, Korea). The wound closure rate was determined using the initial and final wound widths, and the wound closure percentage was calculated by dividing the change in wound width by the initial wound width, as described previously (40).

\section{Soft Agar Colony Formation Assay}

Soft agar colony formation assay was performed to evaluate the anchorage-independent growth ability of the cells. Approximately $5 \times 10^{3}$ cells were suspended in the top soft agar layer $(0.35 \%$ soft agar) and seeded into 6 -well plates, which were pre-coated with $0.5 \%$ base agar. Colonies were allowed to grow at $37^{\circ} \mathrm{C}$ in a $5 \% \mathrm{CO}_{2}$ incubator for $2-3$ weeks, and colony numbers were counted using an ECLIPSE Ti inverted microscope and the NIS-Elements AR (V. 4.0) computer software program (NIKON Instruments Korea, Seoul, Republic of Korea), as described previously (35).

\section{Correlation of CD133/NRF2 With Colorectal Cancer Prognosis}

We used gene expression data of colorectal adenocarcinoma patients $(n=526)$ available at the Cancer Genome Atlas (TCGA) Pan-Cancer Atlas data set. Analyzed data were visualized using the cBioPortal (http://cbioportal.org) to investigate the gene expression levels of NRF2, NQO1, and PIK3CA depending CD133 mRNA levels. Levels of mRNA are presented as RSEM processed using the RNA-Seq by Estimation Maximization (RSEM) algorithm in $\log 2$ scale. In addition, we examined the overall survival rates depending on CD133 expression levels and genetic alterations in CD133 and NRF2. These Kaplan-Meier survival estimates were generated by log-rank nonparametric test in the cBioPortal. P-values are derived from student t-test, and qvalues are obtained from Benjamini-Hochberg procedure.

\section{Statistical Analysis}

We conducted multiple comparison tests for different treatment groups using histomorphometric analysis. The data were analyzed using one-way analysis of variance (ANOVA) followed by Tukey's multiple comparison test to determine which pairs of groups were significantly different. Statistical analyses were conducted using GraphPad Prism 5 (GraphPad Software, Inc., La Jolla, CA, USA). Differences were considered statistically significant at $\mathrm{P}<0.05$.

\section{RESULTS}

\section{High CD133 Levels Are Associated With Facilitated Sphere Growth and CSC Marker Expression}

To examine the relationship between CD133 and CSC-like properties, we first examined the expression levels of CD133 in different carcinoma cell lines. When the basal levels of CD133 were determined in colorectal carcinoma cell line HCT116 and Colo205, pancreatic carcinoma cell line PANC-1 and MIA PaCa2, and breast carcinoma cell line MCF7, HCT116 showed the highest level of CD133 (Supplementary Figures 1A, B, 2B). FACS analysis with CD133-specific antibody showed that $79.8 \%$ of HCT116 total cell fraction expressed CD133 (Figure 1A). In an attempt to investigate the role of CD133 in CSC-like property development, we used a sphere culture system, which was shown to be a CSC-enriched system (42). When HCT116 cells were cultured in ultra-low attachment plates, the transcript level of CD133 increased 3.16-fold in HCT116 spheres and CD133 protein levels were also elevated (Figures 1B, C). Whereas, sphere culture of Colo205, PANC-1, and MIA-PaCa-2 did not show the elevations in CD133, which shows that HCT116 can be used as our experimental model (Supplementary Figures 2A, B). In accordance with CD133 elevation, levels of CSC markers, including KLF4 and ABCG2, were significantly increased in HCT116 colonospheres (Figures 1D, E). We then assessed the association of CD133 with CSC-like properties by silencing CD133 in HCT116 (Figure 1F). The CD133-silenced colonospheres expressed lower levels of KLF4 and ABCG2 than the nonspecific siRNA-transfected colonospheres (Figure 1G). In addition, the number of spheres with a diameter greater than $70 \mu \mathrm{m}$ was markedly diminished by CD133 silencing (Figure 1H). These results showed the critical contribution of CD133 to the development of CSC-like properties in colon cancer cells.

\section{NRF2 Elevation Is Mediated by CD133 in Sphere Cultured Colon Cancer Cells}

In HCT116 colonospheres, transcription levels of NRF2 and its target genes, such as GCLC, AKR1C1, and NQO1 were all increased compared to the HCT116 monolayer (Figure 2A). Increased protein levels of NRF2, GCLC, AKR1C1, and NQO1 
A

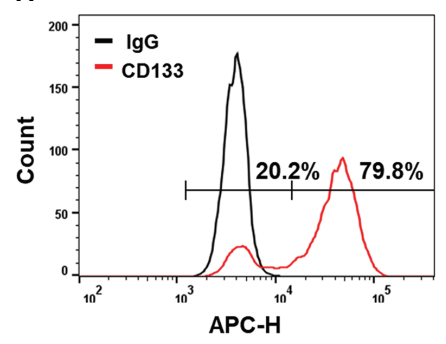

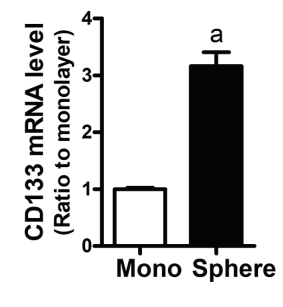
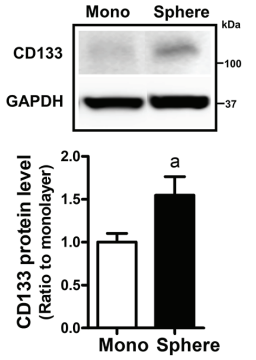

D

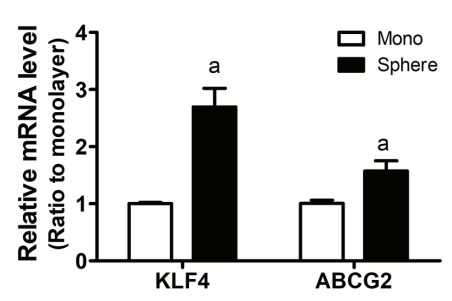

E
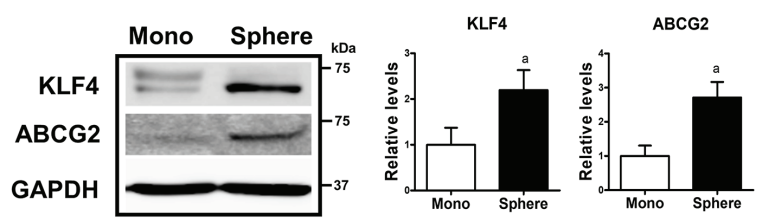

F
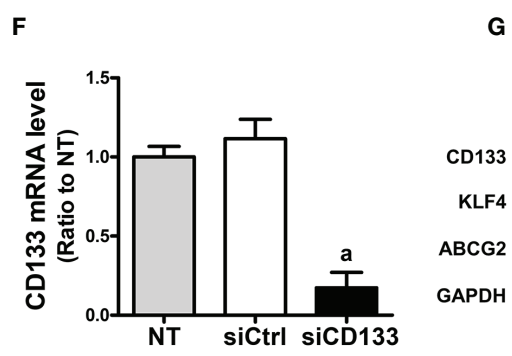

G

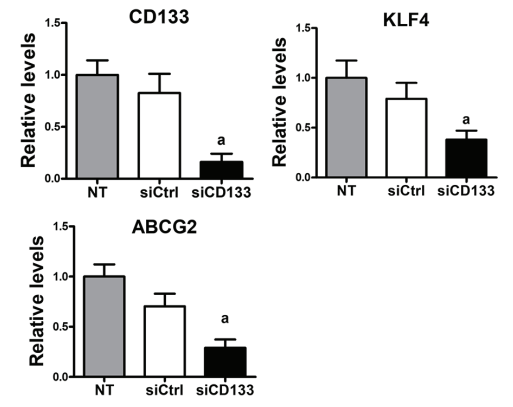

H
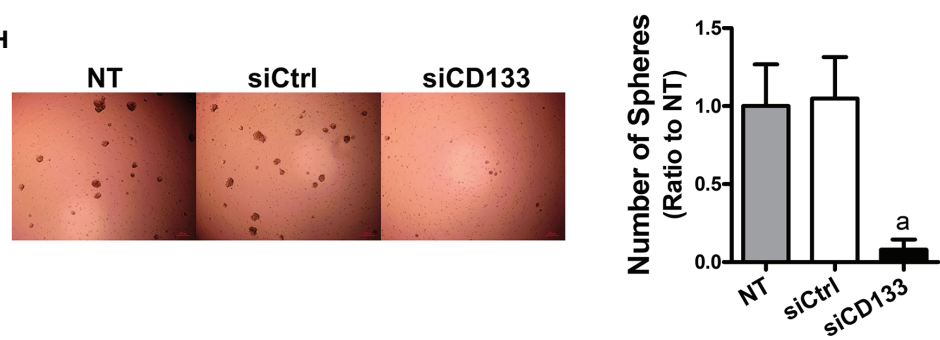

FIGURE 1 | Enhanced CD133 levels in sphere cultured HCT116 cells and their involvement in sphere formation. (A) The presence of CD133-positive cell population in monolayer-cultured HCT116 cells was analyzed using allophycocyanin (APC)-fluorescence-based fluorescence-activated cell sorting method. (B, C) Transcript (B) and protein levels $(\mathbf{C})$ of CD133 were assessed in monolayer and sphere cultured HCT116 cells using relative quantitative reverse transcription-polymerase chain reaction (qRT-PCR) analysis and western blotting. Bar graph represents quantified protein levels from at least three experiments. ${ }^{a} \mathrm{P}<0.05$ compared with the monolayer HCT116. (D, E) The transcript (D) and protein levels (E) of Kruppel-like factor 4 (KLF4) and ATP-binding cassette subfamily G member 2 (ABCG2) in monolayer and sphere HCT116 cells were assessed. Bar graph represents quantified protein levels from at least three experiments. ${ }^{\text {a } P}<0.05$ compared with the monolayer HCT116 cells. (F) Transcript levels of CD133 in the non-transfected (NT), non-specific small interfering RNA (siRNA) (siCtrl)- or CD133-specific siRNA (siCD133)transfected HCT116 cells. ${ }^{a} \mathrm{P}<0.05$ compared with the siCtrl group. (G) HCT116 cell with either the non-specific siRNA (siCtrl) or CD133-specific siRNA (siCD133) transfection, were grown in sphere culture systems and the protein levels of CD133, KLF4, ABCG2 were examined. Bar graph represents quantified protein levels from at least three experiments. (H) Sphere formation was assessed in the non-transfected (NT), non-specific siRNA (siCtrl)- or CD133-specific siRNA (siCD133)transfected HCT116 cells. Number of spheres over $70 \mu \mathrm{m}$ diameter was counted using an image processing ToupView software. ${ }^{\text {a }} \mathrm{P}<0.05 \mathrm{compared}$ with the siCtrl group. Quantification results of western blotting were relative values to the loading control GAPDH. All values represent the mean \pm standard error of the mean (SEM) of more than three experiments.

were also confirmed by western blotting (Figure 2B). Next, we tested the potential involvement of CD133 in NRF2 signaling activation by silencing CD133 in colonospheres. When CD133silenced HCT116 was cultured in sphere conditions, the elevations in NRF2 and its targets GCLC, AKR1C1, and NQO1 were attenuated when compared to the control siRNAtransfected spheres (Figures 2C, D). Whereas, NRF2 mRNA levels, which were elevated in spheres, were not significantly 

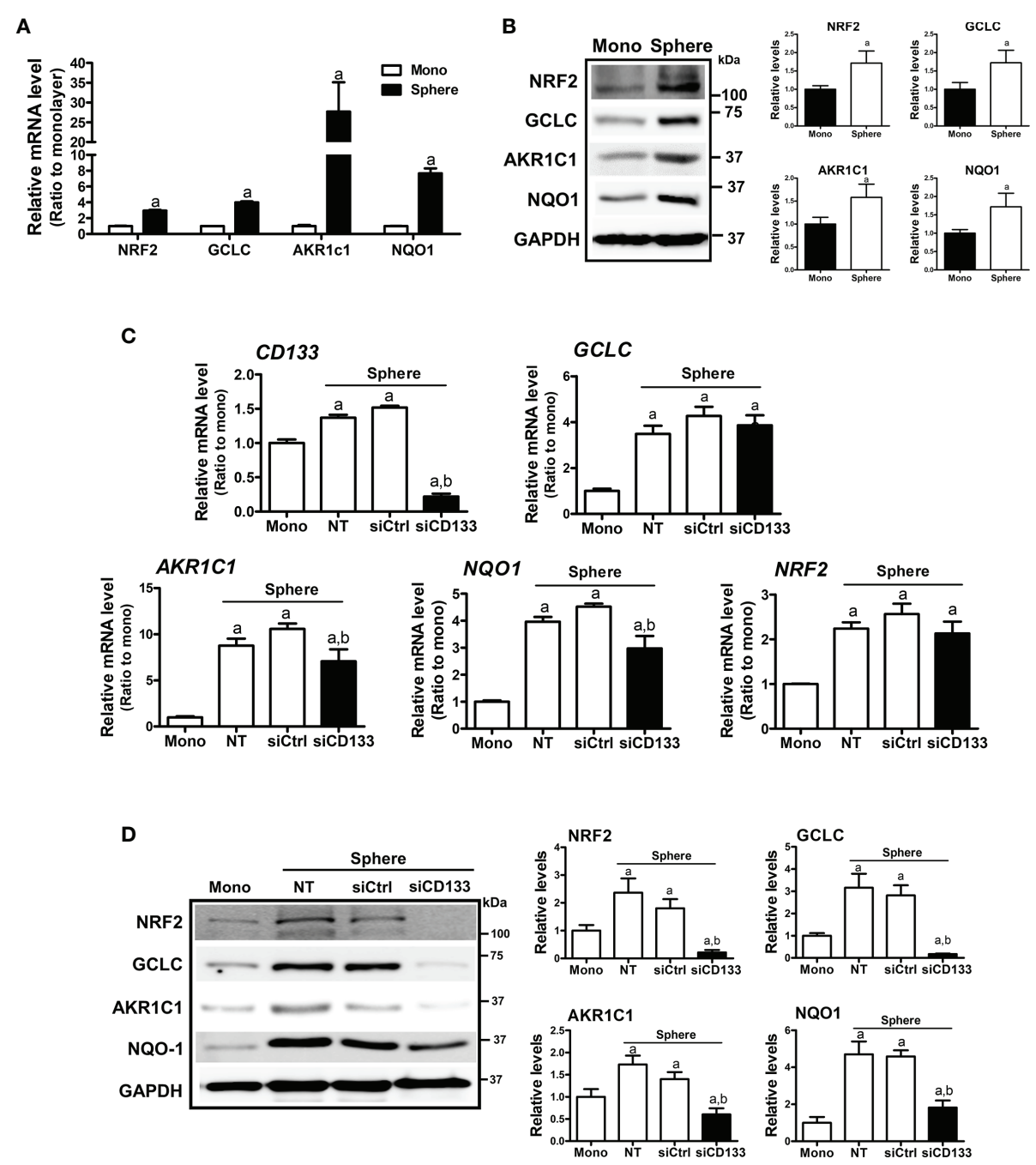

FIGURE 2 | Association of CD133 with NRF2 upregulation in HCT116 spheres. (A) Transcript levels of NRF2, GCLC, AKR1C1, and NQO1 were measured in monolayer and sphere HCT116 cells using a relative qRT-PCR analysis. ${ }^{a} \mathrm{P}<0.05$ compared with the monolayer group. (B) Protein levels of NRF2, GCLC, AKR1C1 and NQO1 were assessed in monolayer and sphere HCT116 cells. Bar graph represents quantified protein levels from at least three experiments. ${ }^{\mathrm{a} P}<0.05$ compared with the monolayer group. (C) HCT116 with either the non-transfection (NT), non-specific siRNA (siCtrl) or CD133-specific siRNA (siCD133) transfection were grown in the sphere culture system, and transcript levels of CD133, GCLC, AKR1C1, NQO1, and NRF2 were measured. ${ }^{\text {a P }<0.05 ~ c o m p a r e d ~}$ with the monolayer. ${ }^{\mathrm{b}} \mathrm{P}<0.05$ compared with the siCtrl group. (D) Protein levels for NRF2, GCLC, AKR1C1, and NQO1 were monitored in sphere cultured HCT116 cells with either the non-specific siRNA (siCtr) or CD133-specific siRNA (siCD133) transfection. Bar graph represents quantified protein levels from at least three experiments. Quantification results of western blotting were relative values to the loading control GAPDH. ${ }^{\mathrm{a}} \mathrm{P}<0.05$ compared with the monolayer.

${ }^{\mathrm{b}} \mathrm{P}<0.05$ compared with the siCtrl group. NT, non-transfection group.

reduced by $C D 133$ silencing. These results showed that the high NRF2 level in sphere-cultured HCT116 cells was attributed to CD133.

\section{Activation of PI3K/AKT Signaling Is Involved in CD133-Mediated Elevation of NRF2}

There have been reports showing that CD133 induces PI3K/ AKT signaling activation in colon cancer cells as well as glioma stem cells $(43,44)$. In addition, AKT-mediated GSK-3 $\beta$ phosphorylation stabilizes NRF2 (27). Based on these results, we monitored the activation levels of AKT/GSK-3 $\beta$ using western blotting to elucidate the molecular events involved in CD133mediated NRF2 elevation in colonospheres. The level of phosphorylated AKT (p-AKT) at Ser473 was higher in colonospheres than in monolayer HCT116 cells, implying the activation of PI3K (Figure 3A). Subsequently, the level of phosphorylated GSK-3 $\beta$ (Ser9), an inactive form of proteasomal NRF2 degradation, was elevated in sphere-cultured HCT116 cells. These results show that CD133-mediated PI3K/AKT activation and resultant GSK-3 $\beta$ inactivation could be a cause of NRF2 elevation in colonospheres. Indeed, when CD133 was silenced, levels of $\mathrm{p}$-AKT and $\mathrm{p}-\mathrm{GSK}-3 \beta$ were reduced in colonospheres (Figure 3B), and treatment with the PI3K inhibitor LY294002 
A

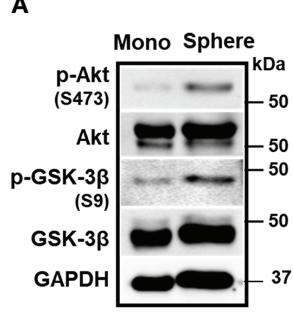

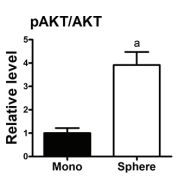

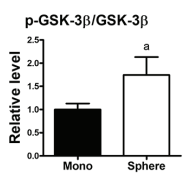

B
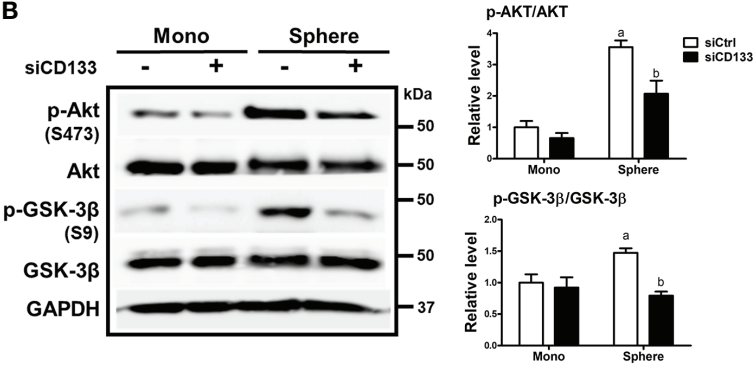

C
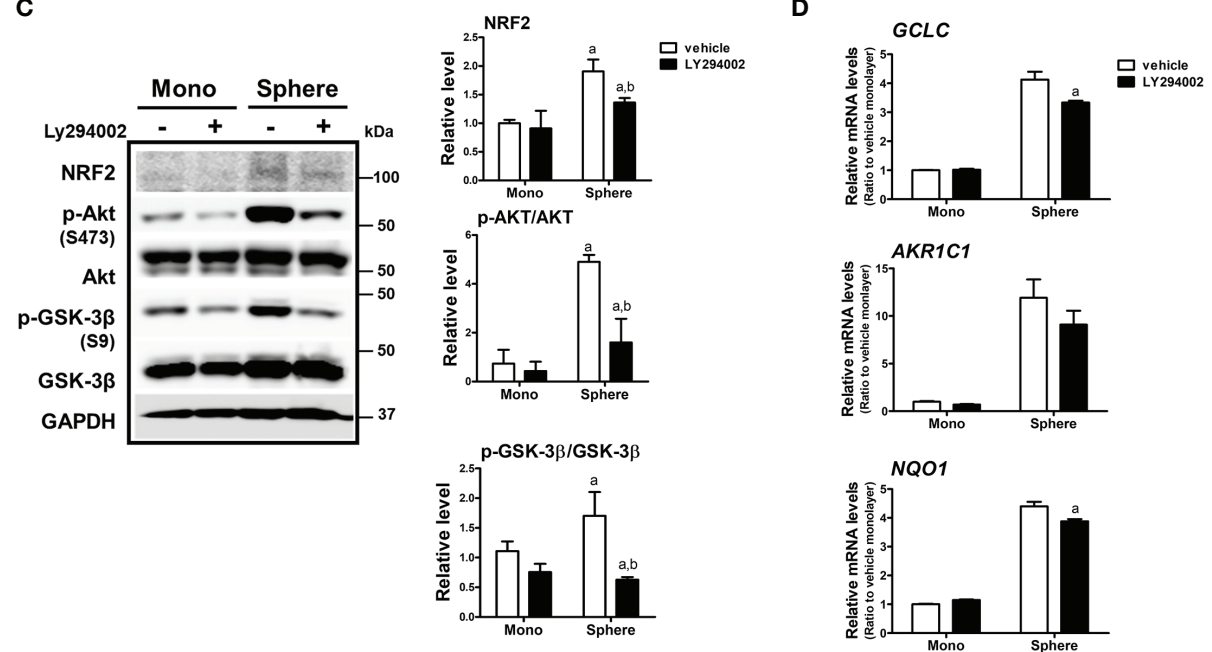

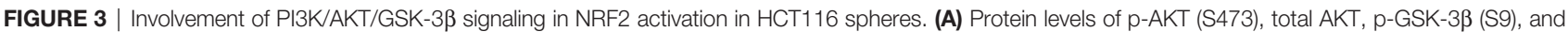
total GSK-3 $\beta$ were determined in monolayer and sphere HCT116 cells. Bar graph represents quantified protein levels from at least three experiments. ${ }^{\text {a } P}<0.05$ compared with the monolayer group. (B) HCT116 cells were transfected with the non-specific siRNA (siCtrl) or CD133-specific siRNA (siCD133) and grown in either

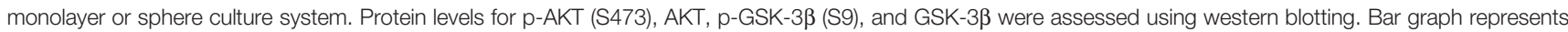
quantified protein levels from at least three experiments. ${ }^{\mathrm{a}} \mathrm{P}<0.05$ compared with the monolayer group. (C) LY294002 (10 $\left.\mu \mathrm{M}\right)$, a pharmacological inhibitor of PI3K,

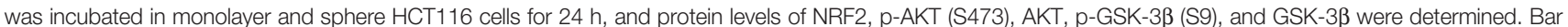
graph represents quantified protein levels from at least three experiments. ${ }^{a} \mathrm{P}<0.05$ compared with the monolayer vehicle group. ${ }^{\mathrm{b}} \mathrm{P}<0.05$ compared with the sphere vehicle group. (D) Transcript levels of GCLC AKR1C1, and NQO1 were measured using a relative qRT-PCR analysis in vehicle- or LY294002-treated cells. ${ }^{\text {aP }}<0.05$ compared with the vehicle-treated sphere group. Quantification results of western blotting were relative values to the loading control GAPDH. Values represent the mean \pm SEM of more than three experiments.

$(10 \mu \mathrm{M})$ repressed these elevations (Figure 3C). Additionally, PI3K inhibitor treatment diminished NRF2 levels and target gene expression levels in HCT116 spheres (Figures 3C, D). These results showed that CD133 contributes to NRF2 upregulation via PI3K/AKT activation and subsequent inhibition of $\mathrm{p}-\mathrm{GSK}-3 \beta$.

\section{NRF2 Contributes to Facilitated Sphere Formation and CSC Marker Elevation}

In order to assess the role of NRF2 in colonosphere formation, NRF2-silenced HCT116 was cultured in sphere culture condition (Figure 4A). NRF2-silencing affected the sphere-forming capacity of HCT116 cells, and the sphere number was reduced (Figure 4B). In line with this, the levels of CSC markers KLF4 and ABCG2 were significantly lower in the NRF2-silenced colonospheres than in the control siRNAtransfected colonospheres (Figure 4C). These results confirmed the functional contribution of NRF2 to the sphereforming capacity.

\section{CD133 ${ }^{\text {high }}$ HCT116 Cells Display Enhanced CSC-Like Properties and NRF2 Activation}

To confirm the relationship between CD133/NRF2 and CSC-like properties, we isolated CD133-positive and CD133-negative cell fractions from total HCT116 cells, and established CD133 ${ }^{\text {low }}$ and CD133 ${ }^{\text {high }}$ cell lines (Figure 5A). These cell lines were cultured for up to 1 month, and high CD133 expression was maintained along with elevated ABCG2 and KLF4 levels (Figure 5B). As phenotypic characteristics, the cell growth rate of CD133 ${ }^{\text {high }}$ HCT 116 cells was higher than that of CD $133^{\text {low }}$ cells (Figure 5C), and anchorage-independent colony formation was enhanced (Figure 5D). In addition, cell motility in the wound healing assay (Figure 5E) and sphere forming capacity (Figure 5F) were higher in CD133 ${ }^{\text {high }}$ HCT116 cells than in CD $133^{\text {low }}$ cells. In line with these CSC-like properties, the cytotoxic response to anticancer treatment was determined using doxorubicin. We observed that 0.5 to $1 \mu \mathrm{M}$ doxorubicin treatment for $24 \mathrm{~h}$ showed similar rates of growth inhibition, and 

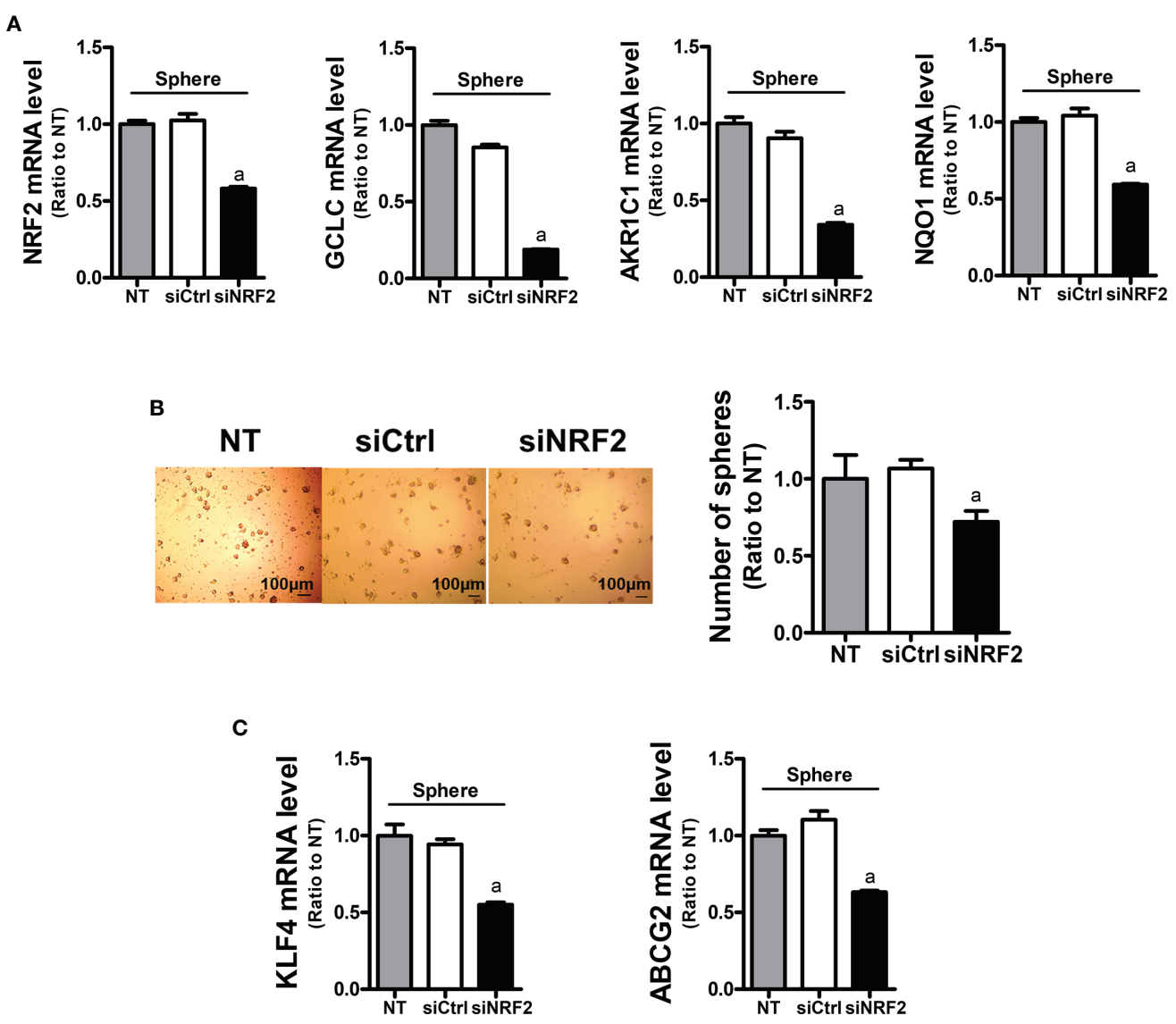

FIGURE 4 | Inhibition of sphere formation and CSC marker levels in NRF2-silenced HCT116 cells. (A) HCT116 cells were transfected with the non-specific siRNA (siCtrl) or NRF2-specific siRNA (siNRF2) and grown for 3 days in sphere culture condition. Levels of NRF2, GCLC, AKR1C1, and NQO1 mRNAs were determined in the siCtrl and siNRF2 spheres. ${ }^{\text {a }} \mathrm{P}<0.05$ compared to the siCtrl group. (B) The siCtrl and siNRF2 HCT116 were grown in sphere culture condition, and sphere formation was assessed. Number of spheres over $70 \mu \mathrm{m}$ diameter was counted using an image processing ToupView software. Values represent the mean \pm SEM from three independent experiments. ${ }^{\text {a }} \mathrm{P}<0.05$ compared to the siCtrl group. (C) Levels of KLF4 and $A B C G 2$ mRNA were assessed in the siCtrl and siNRF2 spheres. ${ }^{\text {a }} \mathrm{P}<0.05$ compared to the siCtrl group. All values in RT-PCR analysis represent the mean \pm SEM from at least three independent experiments. NT, non-transfection group.

the cell growth inhibition by $0.5 \mu \mathrm{M}$ doxorubicin treatment was alleviated in CD133 ${ }^{\text {high }}$ HCT116 cells (Figure 5G). When CD133 levels were silenced in CD133 ${ }^{\text {high }}$ HCT116 cells, the levels of the CSC markers ABCG2 and KLF4, which were elevated in this cell line, were diminished (Figure $\mathbf{5 H}$ ). Additionally, the levels of NRF2 and NQO1 were higher in CD133 ${ }^{\text {high }}$ HCT116 cells than in $\mathrm{CD} 133^{\text {low }}$ cells and were repressed by CD133 silencing (Figure 5H). These results provide direct evidence that the CD133-enriched population exhibited enhanced colony formation, cell migration, colony formation, and drug resistance, which is accompanied by NRF2 activation.

\section{CD133 Alterations Are Associated With NRF2 Elevation and Poor Clinical Outcome in Patients With Colorectal Cancer}

In an attempt to investigate the clinical implication of the linkage between CD133 and NRF2, we analyzed clinical data from the TCGA Pan-Cancer Atlas database using the cBioPortal interface. A total of 526 gene expression data from colorectal adenocarcinoma patients were available in the TCGA PanCancer Atlas database, and 17 cases showed genetic alterations in CD133 gene (missense mutation, 15; frameshift deletion, 1; splice, 1). In CD133-altered group, $11.8 \%$ of patient samples demonstrated NRF2 gene alteration, whereas only $1.4 \%$ of samples showed NRF2 alteration in CD133-unaltered group (data not shown). First, the clinical relationship between CD133 gene alteration $(\mathrm{n}=17)$ and colorectal cancer patients survival was assessed by Kaplan-Meier estimate analysis. It revealed shorter overall survival rate in patients with altered CD133 gene (median survival months=41.36) compared to unaltered CD133 patients (median survival months=83.24) (Figure 6A). Additionally, patients whose tumors have NRF2 or CD133 gene alteration showed shorter overall survival estimates (median survival months $=51.48$ ) than patients with unaltered CD133 gene groups (median survival months=83.24) (Figure 6B). These imply the potential correlation between CD133 gene alteration and clinical outcome of colorectal cancer patients. 
A

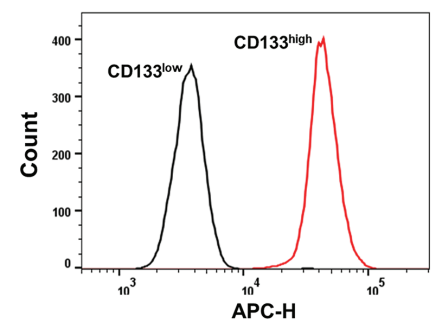

C

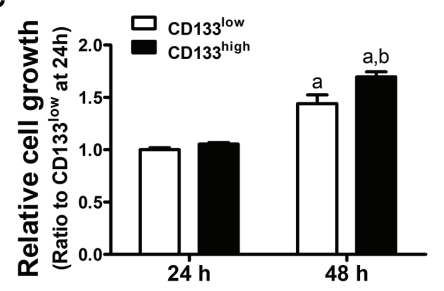

B

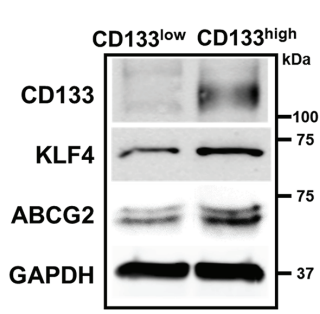

D

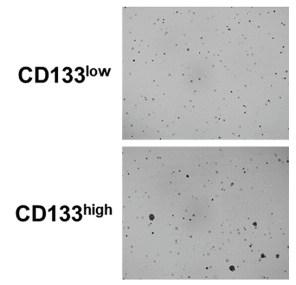

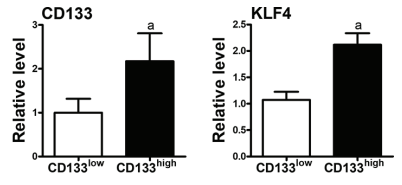
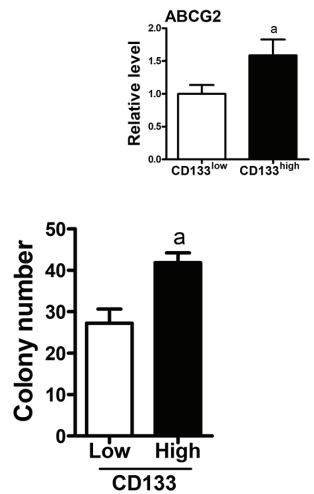

E

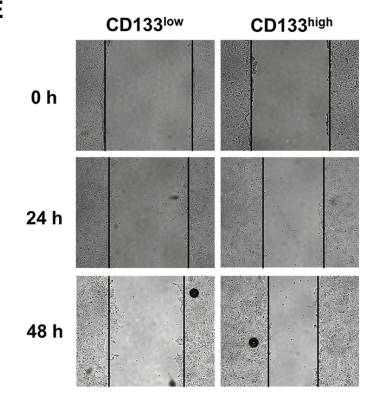

G

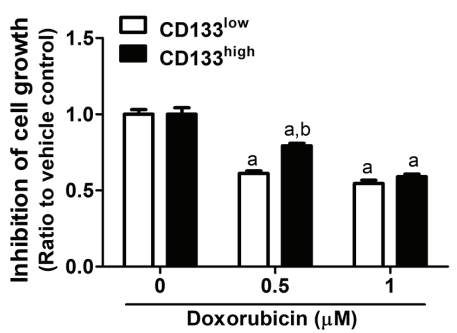

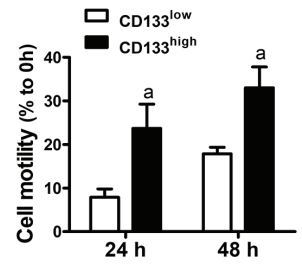

H

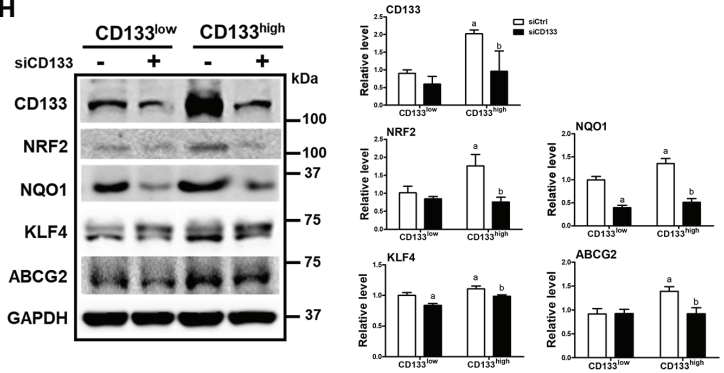

FIGURE 5 | Enhanced CSC-like properties and NRF2 levels in CD133 ${ }^{\text {high }}$ HCT116 fraction. (A) CD133-positive and CD133-negative cell fractions were isolated

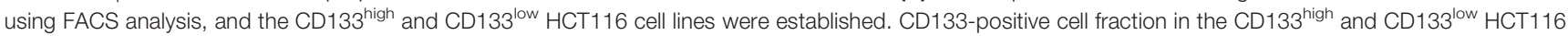
cell lines was assessed following maintenance for 2 weeks. (B) Protein levels of CD133, KLF4, and ABCG2 were determined in established CD133 high and CD133 ${ }^{\text {low }}$ HCT116 cells. Bar graph represents quantified protein levels from at least three experiments. ${ }^{\text {a }} P<0.05$ compared with the CD133 ${ }^{\text {low }}$ cell line. (C) The CD133 high and CD133 $3^{\text {low }}$ HCT116 cells were grown in the absence of fetal bovine serum (FBS) and relative cell growth was assessed using MTT assay after $24 \mathrm{~h}$ and $48 \mathrm{~h}$ of plating. ${ }^{\mathrm{a}} \mathrm{P}<0.05$ compared to each $24 \mathrm{~h}$ group. ${ }^{\mathrm{b}} \mathrm{P}<0.05$ compared to CD133 ${ }^{\text {low }} \mathrm{HCT} 116$ cells. (D) The CD133 ${ }^{\text {high }}$ and CD133 ${ }^{\text {low }}$ HCT116 cells were suspended in the top soft agar layer ( $0.35 \%$ soft agar) and anchorage-independent growth was monitored for 2 weeks. Colony number was counted using an ECLIPSE Ti inverted microscope and the NIS-Elements AR (V. 4.0) software. Bar graph represents quantified results from at least three experiments. ${ }^{a} \mathrm{P}$ $<0.05$ compared to the CD133 low HCT116 cells. (E) Cell migration ability was assessed in the CD133 high and CD133 low HCT116 cells using a wound-healing assay for $24 \mathrm{~h}$ and $48 \mathrm{~h}$. Bar graph represents quantified results from at least three experiments. ${ }^{a} \mathrm{P}<0.05$ compared to the CD133 ${ }^{\text {low }}$ HCT116 cells. (F) $\mathrm{CD} 133^{\text {high }}$ and $\mathrm{CD} 133^{\text {low }} \mathrm{HCT} 116$ cells were grown in sphere culture condition, and sphere formation capacity was assessed by measuring the number and average size of the spheres. Bar graph represents quantified results from at least three experiments. ${ }^{a} \mathrm{P}<0.05$ compared to the CD133 ${ }^{\text {low }}$ HCT116 cells. (G) Inhibition of cell growth was monitored following doxorubicin $(0.5$ and $1 \mu \mathrm{M})$ incubation for $24 \mathrm{~h}$ using MTT assay. Values represent the mean \pm SEM from four independent experiments. ${ }^{\text {a }}<0.05$ compared to the doxorubicin-treated $\mathrm{CD} 133^{\text {low }}$ group. (H) CD133 ${ }^{\text {high }}$ and $\mathrm{CD} 133^{\text {low }} \mathrm{HCT} 116$ cells were transfected with CD133 siRNA and protein levels of CD133, NRF2, NQO1, KLF4, and ABCG2 were determined. Bar graph represents quantified protein levels from at least three experiments. Quantification results of western blotting were relative values to the loading control GAPDH. All values represent the mean \pm SEM from three independent experiments. ${ }^{a} \mathrm{P}<0.05$ compared with the CD133 ${ }^{\text {low }}$ siCtrl group. ${ }^{\mathrm{b}} \mathrm{P}<0.05$ compared with the CD133 ${ }^{\text {high }}$ siCtrl group. 
Among 526 colorectal cancer patients, 52 patients exhibited higher CD133 mRNA levels when compared to unaltered CD133 mRNA group $(n=474)$. The Kaplan-Meier survival analysis showed that the median survival month of patients with high CD133 expression is 81.37 month, which is lower than that of patients with unaltered CD133 expression (83.24 month), although no statistical significance obtained (Figure 6C). In addition, CD133 mRNA levels were associated with increased mRNA levels of NRF2 and NQO1 in these patients. Mean $\log 2$ mRNA expressions of NRF2 were 10.79, 11.21, and 11.28 in CD133-low, unaltered, and CD133-high group, respectively (Figure 6D). NQO1 levels were increased depending on CD133 levels (Figure 6D). PIK3CA mRNA levels were also relatively high in CD133-high group when compared to unaltered group (Figure 6F). These results indicate that CD133 expression is associated with NRF2 signaling activation in colorectal cancers, and further suggested the correlation of

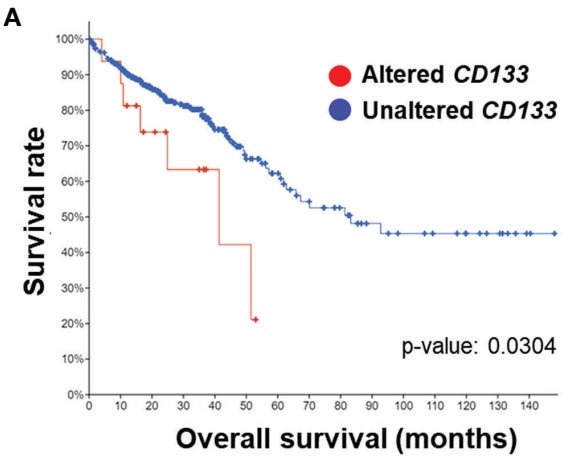

C

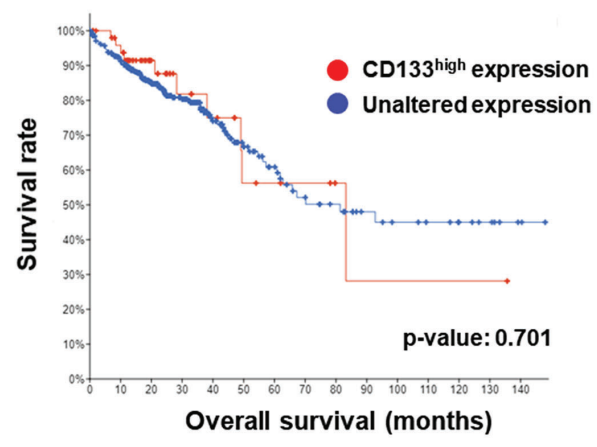

E

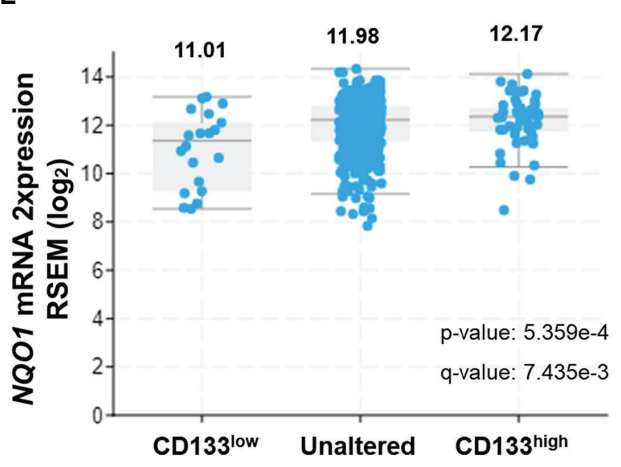

B

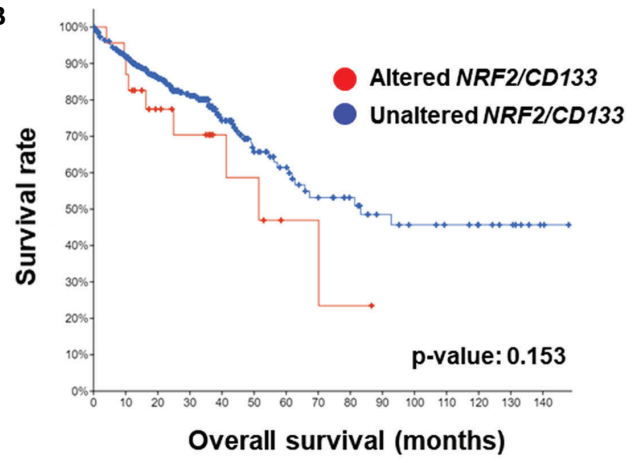

D

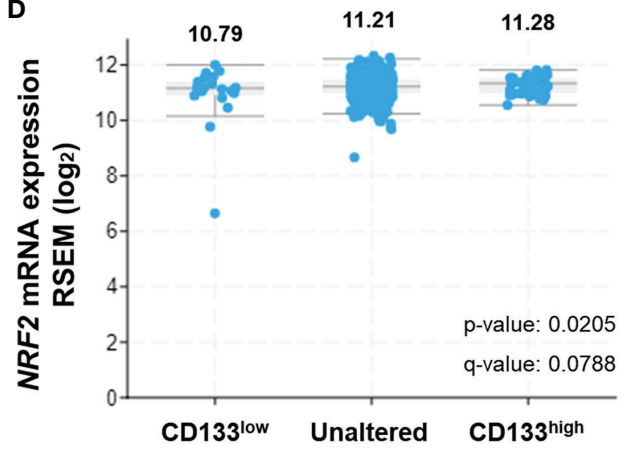

$\mathbf{F}$

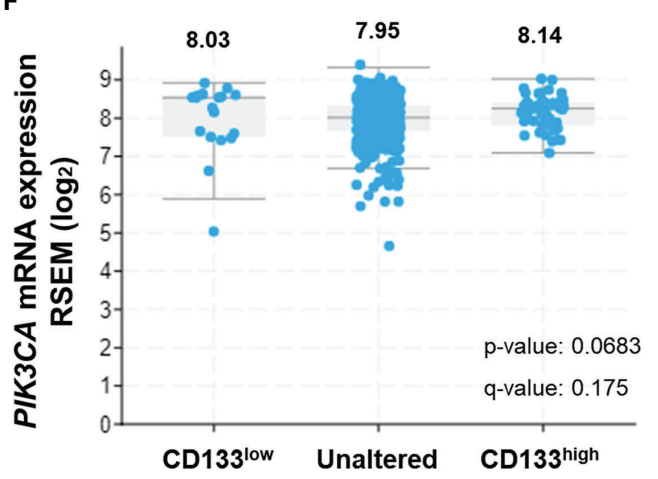

FIGURE 6 | Association of CD133 with NRF2 and clinical outcome of colorectal cancer patients. (A) Overall survival rates of colorectal patients with altered ( $\mathrm{n}=17$ ) vs unaltered $(n=509)$ CD133 gene. (B) Overall survival rates of colorectal patients with altered $(n=24)$ vs unaltered $(n=502)$ NRF2 or CD133 gene. (C) Overall survival rates of colorectal patients with high CD133 $(\mathrm{n}=52)$ vs unaltered (474) mRNA levels. Plots generated by cBioPortal were modified. (D-F) Correlation of CD133 mRNA levels (high CD133, $n=52$; unaltered CD133, $n=454$; low CD133, $n=20$ ) with NRF2 (D), NQO1 (E), and PIK3CA (F) mRNA levels in colorectal tumors. Values are given in (RNA Seq V2 RSEM) in log2. Plots generated by cBioPortal were modified. 
CD133 alteration (mutation and increased expression) with unfavorable clinical outcome.

\section{DISCUSSION}

The major characteristics of CSCs, which include refractory response to conventional chemotherapy and radiotherapy, can be explained by the elevation of drug efflux transporters, enhanced DNA repair ability, and activation of the ROS defense system. The side population of cancer cells, which excludes the fluorescent dye Hoechst 33342, expresses a high level of ABCG2 (BCRP) and displays chemoresistant phenotypes (45). The CD133-high fraction from glioma cells was more resistant to radiotherapy than the CD133-negative fraction, and CD133-high cells activated the molecular event for the DNA damage checkpoint and enhanced DNA repair capacity following radiotherapy (46). The $\mathrm{CD} 44^{+} / \mathrm{CD} 24^{-}$cell fraction was found to be resistant to radiation, and maintenance of low ROS levels was associated with radioresistance (47). CSCs from human breast tumors exhibited less DNA damage and a higher rate of survival after irradiation compared to non-CSCs, and low levels of ROS in CSCs were attributed to increased expression levels of ROS detoxifying systems, such as glutamate-cysteine ligase and GSH synthetase (9). In leukemia with a high frequency of stem cells, ROS levels were low and ROS-scavenging GPX3 levels were high compared to leukemia with a low frequency of stem cells (48). Leukemic stem cells exhibited high levels of FoxoO3a expression, and deletion of foxO blocked the initiation of myeloid leukemia in a mouse model (49). In head and neck squamous cell carcinoma, a CSC marker CD44 variant was found to directly bind to the cystine/glutamate antiporter $\mathrm{xCT}$, thereby increasing GSH synthesis, which is involved in therapy resistance (50). These reports consistently support the importance of the ROS detoxifying system in CSCs for maintaining low ROS levels and high survival under therapy stress.

In the current study, we demonstrated a positive linkage between CD133 and NRF2 in CSC-like properties using the colonosphere culture system and the $\mathrm{CD} 133^{\text {high }}$ subpopulation. Sphere culture of the colorectal cell line HCT116 led to an increase in CD133 expression along with elevated CSC markers, such as KLF4 and ABCG2. CD133-silencing suppressed sphere-forming capacity and expression of KLF4 and ABCG2, which indicates the critical role of CD133 in CSC-like properties development. NRF2 signaling was also upregulated in colonospheres and partly responsible for CSC marker elevation and sphere-forming capacity. Notably, NRF2 activation in colonospheres was CD133-dependent: CD133silencing inhibited NRF2 elevation and attenuated the expression of GCLC, AKR1C1, and NQO1. The relationship between CD133 and NRF2 was confirmed in an isolated CD133 $3^{\text {high }}$ subpopulation from HCT116 cells. Established CD133 ${ }^{\text {high }}$ cell line showed higher doxorubicin resistance, colony formation, sphere formation, and migration capacity than $\mathrm{CD} 133^{\text {low }}$ cell line, and CD133-silencing in CD133 ${ }^{\text {high }}$ cells suppressed NRF2 activation and KLF4 elevation. These in vitro results were supported by clinical relationship between CD133 and NRF2, which were obtained from ATCG database. In colorectal carcinoma patients, overall survival rates were diminished by CD133 and CD133/NRF2 gene alterations, and high CD133 mRNA levels also showed a relationship with reduced overall survival rates. Additionally, high CD133 mRNA levels in colorectal carcinoma showed positive correlations with high transcript levels of NRF2 and NQO1. Taken together, these results suggest that CD133 mediates the activation of NRF2 signaling, which in turn contributes to the CSC-like properties of CD133 ${ }^{\text {high }}$ colon cancers.

As a molecular event for CD133-mediated NRF2 activation, we suggest the involvement of PI3K/AKT/GSK-3 $\beta$. Multiple reports have suggested the activation and contribution of $\mathrm{PI} 3 \mathrm{~K} / \mathrm{AKT}$ signaling in CD133-positive CSCs. Microarray analysis revealed that expression of genes related to the PI3K/ AKT signaling pathway was elevated in sphere-cultured $\mathrm{CD} 33^{+} / \mathrm{CD}_{4} 4^{-}$prostate CSCs, and knockdown of phosphatase and tensin homolog (PTEN) stimulated sphere formation by inhibiting PI3K/AKT signaling (51). Phosphorylation of Tyr828 residue in the cytoplasmic domain of CD133 mediates binding with PI3K, and subsequently activates PI3K/AKT signaling for self-renewal and tumorigenicity of glioma stem cells (44). In line with these findings, an inhibitor of PI3K/AKT suppressed the proliferation and stemness of colon CSCs (52). In our colonosphere system, activation of the PI3K/AKT axis and consequent phosphorylation of GSK-3 $\beta$ at Ser9 were observed. Since AKT-mediated phosphorylation inhibits GSK-3 $\beta$ activity for $\beta$-TCRP-dependent degradation of NRF2, activated PI3K/ AKT signaling is often associated with NRF2 activation in multiple types of cancers. In breast cancers with oncogenic $\mathrm{PI} 3 \mathrm{~K} / \mathrm{AKT}$ activation, NRF2-driven GSH biosynthesis is stimulated, which is required for oxidative stress resistance, tumor spheroid formation, and colony formation. In addition, elevation of NRF2 targets showed a positive correlation with mutation status in the PI3K/AKT pathway (53). In the absence of $K E A P 1$, the deletion of PTEN could further elevate NRF2 levels, which accompanied GSK-3 $\beta$ inactivation via PI3K/AKT activation $(8,54)$. In our study with colonospheres, CD133silencing reduced phosphorylation of AKT/GSK-3 $\beta$, and the PI3K inhibitor LY294002 blocked AKT-mediated GSK-3 $\beta$ phosphorylation and attenuated NRF2 target genes expression. These results suggested that CD133 activates PI3K/AKT signaling, which in turn stabilizes NRF2 protein via GSK-3 $\beta$ inhibition in colonospheres. Of note, we observed that transcript levels of NRF2 were also higher in colonospheres than those in monolayer cultured cells (Figures 2A, C). As NRF2 transcription is regulated by its 5-flanking upstream ARE as a positive feedback loop (55), it can be plausible that PI3K/AKTmediated NRF2 stabilization elevates NRF2 transcription.

Several reports have demonstrated that NRF2 signaling plays a role in CSC maintenance and therapy resistance. In primary glioma stem cells from human glioblastoma tissues, NRF2 knockdown disrupts self-renewal and pluripotency (38). NRF2 signaling is elevated in spheroid cultured breast cancer cells, and 


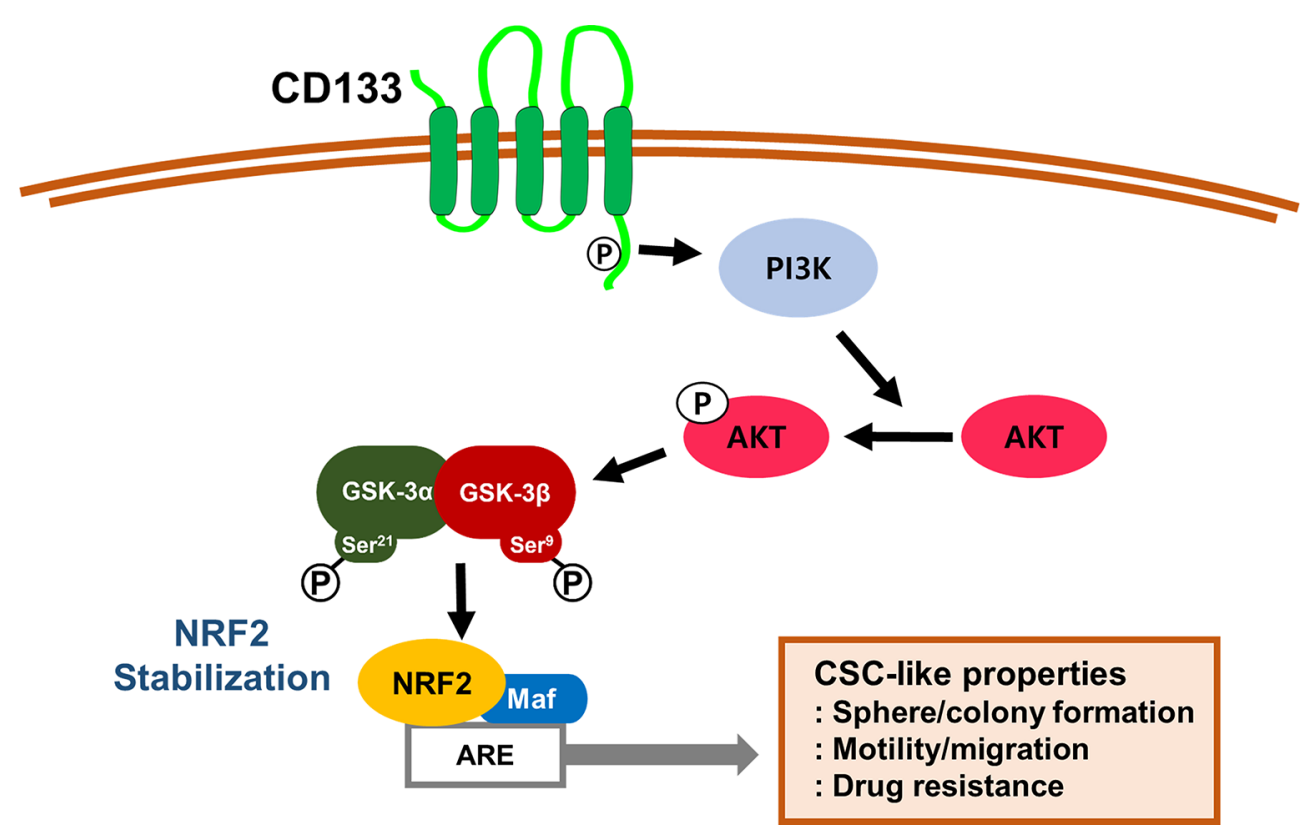

FIGURE 7 | A schematic diagram of the activation of NRF2 signaling and the development of CSC-like properties in CD133-enriched cancer cells. In colonospheres and the CD133-positive cell fraction, high CD133 levels induce PI3K/AKT activation and subsequently inactivate GSK-3 $\beta$ to stabilize NRF2 protein, which results in the acquisition of CSC-like properties, including anchorage-independent growth, sphere formation, facilitated migration, and resistance to anticancer drugs.

high NRF2 levels are required for the maintenance of low ROS levels and taxol resistance (56). Similarly, NRF2 elevation in mammospheres resulted in high levels of drug efflux transporters and antioxidant genes, and NRF2-silencing blocked sphere growth and induced chemosensitization (37). Approximately $3.1 \%$ of cervical CSCs were isolated from tumor specimens, NRF2 was aberrantly upregulated, and NRF2 silencing could sensitize cervical CSCs to DNA damage-induced apoptosis (34).

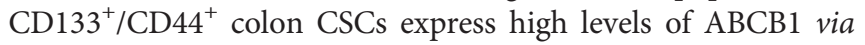
NRF2 elevation, which is associated with doxorubicin resistance (57). In our previous study, CD $44^{\text {high }} \mathrm{CD} 24^{\text {low }}$ breast CSCs exhibited high levels of NRF2 signaling, and NRF2-silencing led to retarded tumor growth, suppression of sphere formation and invasion capacity, and anticancer sensitization (36). The ovarian CSC fraction with high ALDH1 retained low levels of ROS, which was accompanied by NRF2 signaling activation (35). These results suggested a critical role of NRF2 signaling in CSC maintenance and tumor resistance/recurrence and support our current observation of the association between CD133 and NRF2.

Taken together, our results indicate that CD133, a molecular marker of colon CSCs, leads to PI3K/AKT-associated NRF2 activation (Figure 7). High NRF2 levels in spheroid cultured HCT116 cells and the CD133 ${ }^{\text {high }}$ subpopulation contributed to the aggressive CSC phenotypes, including anticancer resistance, sphere formation, anchorage-independent colony formation, and migration potential. Therefore, the NRF2 axis might be a promising target for the inhibition of therapeutic resistance and enhancement of survival capacity under stress conditions in CD133 $3^{\text {high }}$ CSCs.

\section{DATA AVAILABILITY STATEMENT}

The original contributions presented in the study are included in the article/Supplementary Material. Further inquiries can be directed to the corresponding author.

\section{AUTHOR CONTRIBUTIONS}

JP carried out the experiment with support from SKK and SPH. SKK and SPH contributed to sample preparation, data analysis, and figure preparation. JP and MKK wrote the manuscript with the help from SKK and SPH. BHC contributed to data analysis and figure preparation. MKK conceived the original idea and supervised the project. All authors provided critical feedback and helped shape the research, analysis and manuscript preparation. All authors contributed to the article and approved the submitted version.

\section{FUNDING}

This work was supported by the National Research Foundation of Korea (NRF) grant funded by the Korean government (MSIT) (2018R1A2A1A05078894, 2018R1A6A1A03025108).

\section{SUPPLEMENTARY MATERIAL}

The Supplementary Material for this article can be found online at: https://www.frontiersin.org/articles/10.3389/fonc.2021.808300/ full\#supplementary-material 


\section{REFERENCES}

1. Bonnet D, Dick JE. Human Acute Myeloid Leukemia is Organized as a Hierarchy That Originates From a Primitive Hematopoietic Cell. Nat Med (1997) 3(7):730-7. doi: 10.1038/nm0797-730

2. Huang R, Rofstad EK. Cancer Stem Cells (CSCs), Cervical CSCs and Targeted Therapies. Oncotarget (2017) 8(21):35351-67. doi: 10.18632/oncotarget. 10169

3. Chen W, Dong J, Haiech J, Kilhoffer M-C, Zeniou M. Cancer Stem Cell Quiescence and Plasticity as Major Challenges in Cancer Therapy. Stem Cells Int (2016) 2016:1740936-. doi: 10.1155/2016/1740936

4. Shahriyari L, Komarova NL. Symmetric vs. Asymmetric Stem Cell Divisions: An Adaptation Against Cancer? PloS One (2013) 8(10):e76195. doi: 10.1371/ journal.pone.0076195

5. Khan AQ, Ahmed EI, Elareer NR, Junejo K, Steinhoff M, Uddin S. Role of miRNA-Regulated Cancer Stem Cells in the Pathogenesis of Human Malignancies. Cells (2019) 8(8):840. doi: 10.3390/cells8080840

6. Zhao J. Cancer Stem Cells and Chemoresistance: The Smartest Survives the Raid. Pharmacol Ther (2016) 160:145-58. doi: 10.1016/j.pharmthera.2016. 02.008

7. Tan BT, Park CY, Ailles LE, Weissman IL. The Cancer Stem Cell Hypothesis: A Work in Progress. Lab Invest (2006) 86(12):1203-7. doi: 10.1038/ labinvest. 3700488

8. Abdullah LN, Chow EK-H. Mechanisms of Chemoresistance in Cancer Stem Cells. Clin Trans Med (2013) 2(1):3-. doi: 10.1186/2001-1326-2-3

9. Diehn M, Cho RW, Lobo NA, Kalisky T, Dorie MJ, Kulp AN, et al. Association of Reactive Oxygen Species Levels and Radioresistance in Cancer Stem Cells. Nature (2009) 458(7239):780-3. doi: 10.1038/nature07733

10. Villodre ES, Kipper FC, Pereira MB, Lenz G. Roles of OCT4 in Tumorigenesis, Cancer Therapy Resistance and Prognosis. Cancer Treat Rev (2016) 51:1-9. doi: 10.1016/j.ctrv.2016.10.003

11. Yu F, Li J, Chen H, Fu J, Ray S, Huang S, et al. Kruppel-Like Factor 4 (KLF4) is Required for Maintenance of Breast Cancer Stem Cells and for Cell Migration and Invasion. Oncogene (2011) 30(18):2161-72. doi: 10.1038/ onc.2010.591

12. Weigmann A, Corbeil D, Hellwig A, Huttner WB. Prominin, a Novel Microvilli-Specific Polytopic Membrane Protein of the Apical Surface of Epithelial Cells, is Targeted to Plasmalemmal Protrusions of non-Epithelial Cells. Proc Natl Acad Sci USA (1997) 94(23):12425-30. doi: 10.1073/ pnas.94.23.12425

13. Miraglia S, Godfrey W, Yin AH, Atkins K, Warnke R, Holden JT, et al. A Novel Five-Transmembrane Hematopoietic Stem Cell Antigen: Isolation, Characterization, and Molecular Cloning. Blood (1997) 90(12):5013-21. doi: 10.1182/blood.V90.12.5013

14. Aghajani M, Mansoori B, Mohammadi A, Asadzadeh Z, Baradaran B. New Emerging Roles of CD133 in Cancer Stem Cell: Signaling Pathway and miRNA Regulation. J Cell Physiol (2019) 234(12):21642-61. doi: 10.1002/ jcp. 28824

15. Ricci-Vitiani L, Lombardi DG, Pilozzi E, Biffoni M, Todaro M, Peschle C, et al. Identification and Expansion of Human Colon-Cancer-Initiating Cells. Nature (2007) 445(7123):111-5. doi: 10.1038/nature05384

16. O'Brien CA, Pollett A, Gallinger S, Dick JE. A Human Colon Cancer Cell Capable of Initiating Tumour Growth in Immunodeficient Mice. Nature (2007) 445(7123):106-10. doi: 10.1038/nature05372

17. Horst D, Kriegl L, Engel J, Kirchner T, Jung A. CD133 Expression is an Independent Prognostic Marker for Low Survival in Colorectal Cancer. $\mathrm{Br} \mathrm{J}$ Cancer (2008) 99(8):1285-9. doi: 10.1038/sj.bjc.6604664

18. Nomura A, Banerjee S, Chugh R, Dudeja V, Yamamoto M, Vickers SM, et al. CD133 Initiates Tumors, Induces Epithelial-Mesenchymal Transition and Increases Metastasis in Pancreatic Cancer. Oncotarget (2015) 6(10):8313-22. doi: 10.18632/oncotarget.3228

19. Bertolini G, Roz L, Perego P, Tortoreto M, Fontanella E, Gatti L, et al. Highly Tumorigenic Lung Cancer CD133+ Cells Display Stem-Like Features and are Spared by Cisplatin Treatment. Proc Natl Acad Sci USA (2009) 106 (38):16281-6. doi: 10.1073/pnas.0905653106

20. Ma L, Liu T, Jin Y, Wei J, Yang Y, Zhang H. ABCG2 is Required for SelfRenewal and Chemoresistance of CD133-Positive Human Colorectal Cancer Cells. Tumour Biol (2016) 37(9):12889-96. doi: 10.1007/s13277-016-5209-5
21. Baird L, Yamamoto M. The Molecular Mechanisms Regulating the KEAP1NRF2 Pathway. Mol Cell Biol (2020) 40(13):e00099-20. doi: 10.1128/ mcb.00099-20

22. Cho HY, Kleeberger SR. Mitochondrial Biology in Airway Pathogenesis and the Role of NRF2. Arch Pharm Res (2020) 43(3):297-320. doi: 10.1007/ s12272-019-01182-5

23. Otsuki A, Yamamoto M. Cis-Element Architecture of Nrf2-Smaf Heterodimer Binding Sites and its Relation to Diseases. Arch Pharm Res (2020) 43(3):27585. doi: 10.1007/s12272-019-01193-2

24. Hayes JD, Dinkova-Kostova AT. The Nrf2 Regulatory Network Provides an Interface Between Redox and Intermediary Metabolism. Trends Biochem Sci (2014) 39(4):199-218. doi: 10.1016/j.tibs.2014.02.002

25. Shaw P, Chattopadhyay A. Nrf2-ARE Signaling in Cellular Protection: Mechanism of Action and the Regulatory Mechanisms. J Cell Physiol (2020) 235(4):3119-30. doi: 10.1002/jcp.29219

26. Cuadrado A, Rojo AI, Wells G, Hayes JD, Cousin SP, Rumsey WL, et al. Therapeutic Targeting of the NRF2 and KEAP1 Partnership in Chronic Diseases. Nat Rev Drug Discov (2019) 18(4):295-317. doi: 10.1038/s41573018-0008-x

27. Chowdhry S, Zhang Y, McMahon M, Sutherland C, Cuadrado A, Hayes JD. Nrf2 is Controlled by Two Distinct Beta-TrCP Recognition Motifs in its Neh6 Domain, One of Which can be Modulated by GSK-3 Activity. Oncogene (2013) 32(32):3765-81. doi: 10.1038/onc.2012.388

28. Salazar M, Rojo AI, Velasco D, de Sagarra RM, Cuadrado A. Glycogen Synthase Kinase- $3 \beta$ Inhibits the Xenobiotic and Antioxidant Cell Response by Direct Phosphorylation and Nuclear Exclusion of the Transcription Factor Nrf2. J Biol Chem (2006) 281(21):14841-51. doi: 10.1074/jbc.M513737200

29. Cuadrado A. Structural and Functional Characterization of Nrf2 Degradation by Glycogen Synthase Kinase 3/ $\beta$-TrCP. Free Radical Biol Med (2015) 88:14757. doi: 10.1016/j.freeradbiomed.2015.04.029

30. Rojo AI, Sagarra M, Cuadrado A. GSK-3 $\beta$ Down-Regulates the Transcription Factor Nrf2 After Oxidant Damage: Relevance to Exposure of Neuronal Cells to Oxidative Stress. J Neurochem (2008) 105(1):192-202. doi: 10.1111/j.14714159.2007.05124.x

31. Choi B-H, Kim JM, Kwak M-K. The Multifaceted Role of NRF2 in Cancer Progression and Cancer Stem Cells Maintenance. Arch Pharmacal Res (2021) 44(3):263-80. doi: 10.1007/s12272-021-01316-8

32. Rojo de la Vega M, Chapman E, Zhang DD. NRF2 and the Hallmarks of Cancer. Cancer Cell (2018) 34(1):21-43. doi: 10.1016/j.ccell.2018.03.022

33. Torrente L, DeNicola GM. Targeting NRF2 and Its Downstream Processes: Opportunities and Challenges. Annu Rev Pharmacol Toxicol (2022) 62:279300. doi: 10.1146/annurev-pharmtox-052220-104025

34. Jia Y, Chen J, Zhu H, Jia ZH, Cui MH. Aberrantly Elevated Redox Sensing Factor Nrf2 Promotes Cancer Stem Cell Survival via Enhanced Transcriptional Regulation of ABCG2 and Bcl-2/Bmi-1 Genes. Oncol Rep (2015) 34(5):2296-304. doi: 10.3892/or.2015.4214

35. Kim D, Choi BH, Ryoo IG, Kwak MK. High NRF2 Level Mediates Cancer Stem Cell-Like Properties of Aldehyde Dehydrogenase (ALDH)-High Ovarian Cancer Cells: Inhibitory Role of All-Trans Retinoic Acid in ALDH/ NRF2 Signaling. Cell Death Dis (2018) 9(9):896. doi: 10.1038/s41419-0180903-4

36. Ryoo IG, Choi BH, Ku SK, Kwak MK. High CD44 Expression Mediates P62Associated NFE2L2/NRF2 Activation in Breast Cancer Stem Cell-Like Cells: Implications for Cancer Stem Cell Resistance. Redox Biol (2018) 17:246-58. doi: 10.1016/j.redox.2018.04.015

37. Ryoo I-G, Choi B-H, Kwak M-K. Activation of NRF2 by P62 and Proteasome Reduction in Sphere-Forming Breast Carcinoma Cells. Oncotarget (2015) 6 (10):8167-84. doi: 10.18632/oncotarget.3047

38. Zhu J, Wang H, Sun Q, Ji X, Zhu L, Cong Z, et al. Nrf2 is Required to Maintain the Self-Renewal of Glioma Stem Cells. BMC Cancer (2013) 13(1):380 doi: 10.1186/1471-2407-13-380

39. Wu T, Harder BG, Wong PK, Lang JE, Zhang DD. Oxidative Stress, Mammospheres and Nrf2-New Implication for Breast Cancer Therapy? Mol Carcinog (2015) 54(11):1494-502. doi: 10.1002/mc.22202

40. Ryu D, Lee JH, Kwak MK. NRF2 Level is Negatively Correlated With TGF- $\beta 1$ Induced Lung Cancer Motility and Migration via NOX4-ROS Signaling. Arch Pharm Res (2020) 43(12):1297-310. doi: 10.1007/s12272-020-01298-Z 
41. Choi JH, Jin SW, Lee GH, Cho SM, Jeong HG. Orostachys Japonicus Ethanol Extract Inhibits 2,4-Dinitrochlorobenzene-Induced Atopic Dermatitis-Like Skin Lesions in NC/Nga Mice and TNF- $\alpha /$ IFN- $\gamma$-Induced TARC Expression in HaCaT Cells. Toxicol Res (2020) 36(2):99-108. doi: 10.1007/s43188-01900026-0

42. Hubert CG, Rivera M, Spangler LC, Wu Q, Mack SC, Prager BC, et al. A Three-Dimensional Organoid Culture System Derived From Human Glioblastomas Recapitulates the Hypoxic Gradients and Cancer Stem Cell Heterogeneity of Tumors Found In Vivo. Cancer Res (2016) 76(8):2465-77. doi: 10.1158/0008-5472.Can-15-2402

43. Shimozato O, Waraya M, Nakashima K, Souda H, Takiguchi N, Yamamoto H, et al. Receptor-Type Protein Tyrosine Phosphatase Kappa Directly Dephosphorylates CD133 and Regulates Downstream AKT Activation. Oncogene (2015) 34(15):1949-60. doi: 10.1038/onc.2014.141

44. Wei Y, Jiang Y, Zou F, Liu Y, Wang S, Xu N, et al. Activation of PI3K/Akt Pathway by CD133-P85 Interaction Promotes Tumorigenic Capacity of Glioma Stem Cells. Proc Natl Acad Sci USA (2013) 110(17):6829-34. doi: 10.1073/pnas.1217002110

45. Hadnagy A, Gaboury L, Beaulieu R, Balicki D. SP Analysis may be Used to Identify Cancer Stem Cell Populations. Exp Cell Res (2006) 312(19):3701-10. doi: 10.1016/j.yexcr.2006.08.030

46. Bao S, Wu Q, McLendon RE, Hao Y, Shi Q, Hjelmeland AB, et al. Glioma Stem Cells Promote Radioresistance by Preferential Activation of the DNA Damage Response. Nature (2006) 444(7120):756. doi: 10.1038/nature05236

47. Phillips TM, McBride WH, Pajonk F. The Response of CD24(-/Low)/CD44+ Breast Cancer-Initiating Cells to Radiation. J Natl Cancer Inst (2006) 98 (24):1777-85. doi: 10.1093/jnci/djj495

48. Herault O, Hope KJ, Deneault E, Mayotte N, Chagraoui J, Wilhelm BT, et al. A Role for GPx3 in Activity of Normal and Leukemia Stem Cells. J Exp Med (2012) 209(5):895-901. doi: 10.1084/jem.20102386

49. Naka K, Hoshii T, Muraguchi T, Tadokoro Y, Ooshio T, Kondo Y, et al. TGFBeta-FOXO Signalling Maintains Leukaemia-Initiating Cells in Chronic Myeloid Leukaemia. Nature (2010) 463(7281):676-80. doi: 10.1038/ nature 08734

50. Ishimoto T, Nagano O, Yae T, Tamada M, Motohara T, Oshima H, et al. CD44 Variant Regulates Redox Status in Cancer Cells by Stabilizing the xCT Subunit of System Xc(-) and Thereby Promotes Tumor Growth. Cancer Cell (2011) 19(3):387-400. doi: 10.1016/j.ccr.2011.01.038

51. Dubrovska A, Kim S, Salamone RJ, Walker JR, Maira SM, García-Echeverría $\mathrm{C}$, et al. The Role of PTEN/Akt/PI3K Signaling in the Maintenance and
Viability of Prostate Cancer Stem-Like Cell Populations. Proc Natl Acad Sci USA (2009) 106(1):268-73. doi: 10.1073/pnas.0810956106

52. Chen J, Shao R, Li F, Monteiro M, Liu JP, Xu ZP, et al. PI3K/Akt/mTOR Pathway Dual Inhibitor BEZ235 Suppresses the Stemness of Colon Cancer Stem Cells. Clin Exp Pharmacol Physiol (2015) 42(12):1317-26. doi: 10.1111/ 1440-1681.12493

53. Lien EC, Lyssiotis CA, Juvekar A, Hu H, Asara JM, Cantley LC, et al. Glutathione Biosynthesis is a Metabolic Vulnerability in PI(3)K/Akt-Driven Breast Cancer. Nat Cell Biol (2016) 18(5):572-8. doi: 10.1038/ncb3341

54. Mitsuishi Y, Taguchi K, Kawatani Y, Shibata T, Nukiwa T, Aburatani H, et al. Nrf2 Redirects Glucose and Glutamine Into Anabolic Pathways in Metabolic Reprogramming. Cancer Cell (2012) 22(1):66-79. doi: 10.1016/j.ccr. 2012.05.016

55. Kwak MK, Itoh K, Yamamoto M, Kensler TW. Enhanced Expression of the Transcription Factor Nrf2 by Cancer Chemopreventive Agents: Role of Antioxidant Response Element-Like Sequences in the Nrf2 Promoter. Mol Cell Biol (2002) 22(9):2883-92. doi: 10.1128/mcb.22.9.2883-2892.2002

56. Wu T, Harder BG, Wong PK, Lang JE, Zhang DD. Oxidative Stress, Mammospheres and Nrf2-new Implication for Breast Cancer Therapy? Mol Carcinog (2014) 54(11):1494-502. doi: 10.1002/mc.22202

57. Goto S, Kawabata T, Li TS. Enhanced Expression of ABCB1 and Nrf2 in CD133-Positive Cancer Stem Cells Associates With Doxorubicin Resistance. Stem Cells Int (2020) 2020:8868849. doi: 10.1155/2020/8868849

Conflict of Interest: The authors declare that the research was conducted in the absence of any commercial or financial relationships that could be construed as a potential conflict of interest.

Publisher's Note: All claims expressed in this article are solely those of the authors and do not necessarily represent those of their affiliated organizations, or those of the publisher, the editors and the reviewers. Any product that may be evaluated in this article, or claim that may be made by its manufacturer, is not guaranteed or endorsed by the publisher.

Copyright (c) 2022 Park, Kim, Hallis, Choi and Kwak. This is an open-access article distributed under the terms of the Creative Commons Attribution License (CC BY). The use, distribution or reproduction in other forums is permitted, provided the original author(s) and the copyright owner(s) are credited and that the original publication in this journal is cited, in accordance with accepted academic practice. No use, distribution or reproduction is permitted which does not comply with these terms. 